\title{
Preliminary characterization of a monoclonal antibody (AS-2) against cell cycle related proteins
}

\author{
Stefano Nigro, Anna Rapallo, Angela Di Vinci, Elio Geido, Roberto Orecchia and \\ Walter Giaretti * \\ Laboratory of Biophysics and Cytometry, National Institute for Cancer Research, Genoa, Italy
}

Received 27 February 1998

Revised 6 July 1998

Accepted 6 July 1998

\begin{abstract}
A monoclonal antibody (AS-2) raised by using isolated nuclei from a human erythroleukemia cell line as immunogen is described.

AS-2 was of IgM type and recognized proteins present in both isolated cytoplasms and nuclei. The molecular weight of the AS-2 recognized proteins in the cytoplasm was $200 \mathrm{kDa}$ and 70 and $60 \mathrm{kDa}$ in the nucleus. The relative amount of these proteins were measured simultaneously with DNA content by flow cytometry. We found the highest protein content (or stainability) for both cells and nuclei in late-G1, S and G2, at approximately the same level, and the lowest content in M and early-G1. Sorting based on DNA content and AS-2 associated fluorescence helped identifying the staining pattern of cells and nuclei. Interphase isolated nuclei and cell cytoplasms were characterized by interdispersed staining over the entire surfaces while mitoses showed two dots only. The present preliminary data indicate that the proteins recognized by the AS- 2 monoclonal are cell cycle related and suggest that in mitoses they are associated with the centrosomes.
\end{abstract}

Keywords: Monoclonal antibodies, flow cytometry, cell cycle

\section{Introduction}

The number of monoclonal antibodies (Mabs) against nuclear antigens suitable for use in coupling with quantitative image (ICM) and flow cytometry (FCM) is still limited [1-6,7].

The production of new Mabs directed against cell cycle dependent nuclear antigens of human normal and tumor cells may be useful to better understand nuclear structure and function $[4,8]$. These Mabs may also clearly be used in the field of quantitative pathology for clinical applications as, for examples, in cancer diagnosis and prognosis [9].

We have produced a series of Mabs immunizing mice with nuclear extracts obtained from the K562 cell line. FCM was used in coupling with measurement of DNA content for screening, in order to select immediately the Mabs associated to proteins that were clearly cell cycle dependent in their expression and/or stainability.

\footnotetext{
${ }^{*}$ Correspondence to: Dr W. Giaretti, Laboratorio di Biofisica-Citometria, Istituto Nazionale per la Ricerca sul Cancro (I.S.T.), Largo Rosanna Benzi n. 10, 16132 Genova, Italia. Tel.: \#10 5600969; Fax: \#10 5600711.
} 
Our attention has been focused on a Mab that we preliminarily describe here (AS-2). As it will be seen, AS-2 showed a clear cell cycle dependance and recognized three proteins with different molecular weights and sub-cellular localization.

\section{Materials and methods}

\subsection{Production and FCM screening of Mabs against nuclear antigens}

\subsubsection{Isolation of nuclei}

We used human K562 erythroleukemia cells grown in standard conditions (RPMI 1640 medium (Gibco, Grand Island, NY, USA), 10\% fetal calf serum (FCS), $0.5 \%$ gentamicin and $1 \%$ glutamine, $5 \% \mathrm{CO}_{2}, 37^{\circ} \mathrm{C}$ ) and HeLa cells grown in minimum essential medium (DMEM) (Gibco, Grand Island, NY, USA) supplemented with $10 \%$ FCS, $0.5 \%$ gentamicin and $1 \%$ glutamine.

Cell harvest was done at the 3rd day after seeding to obtain a large fraction of proliferating cells. The cells, washed two times with phosphate buffer saline (PBS) Dulbecco's MEM, were resuspended in $2 \mathrm{ml}$ solution A (solution A: $\mathrm{NaCl} 100 \mathrm{mM}$; sucrose $300 \mathrm{mM}$; piperazine-N-N'-bis 2-ethanesulfonic acid (PIPES) $10 \mathrm{mM} ; \mathrm{MgCl}_{2} 3 \mathrm{mM} ; \mathrm{pH}$ 6.8) containing 0.5\% Triton X 100 and incubated on ice for 30 min, to obtain cytoplasmic lysis. Washing was done once in PBS, followed by incubation in PBS containing both DNase I and RNase at $0.5 \mathrm{mg} / \mathrm{ml}$ at $4^{\circ} \mathrm{C}$ for $30 \mathrm{~min}$. Washing was done twice and nuclei concentration was adjusted to $50 \times 10^{6}$ nuclei/ml in Freund's adjuvant solution (Sigma, St. Louis, USA) to be used for mice immunization.

\subsubsection{Mice immunization, cell fusion and FCM hybridoma screening}

Immunization was performed with purified/sonicated K562 nuclei using females of Balb/C mice three months old. After five booster injections, mice were sacrificed and the spleens were removed. Hybridomas, derived from the fusion of spleen cells and P3 murine-myeloma cells, were obtained following standard procedures [10]. Supernatant of growing hybridoma clones were isolated and screened by FCM. The positive clones were subcloned by limiting dilution and the supernatants were again screened as previously.

\subsubsection{Colcemid block/release}

In G2/M-block/release experiments, colcemid at $0.1 \mu \mathrm{g} / \mathrm{ml}$ was added to the cell culture medium of proliferating cells. Cells were collected after $1.5 \mathrm{~h}$ of treatment (block) or were washed and added with fresh medium before being harvested $2 \mathrm{~h}$ after washing (release).

\subsubsection{Flow cytometry}

We used FCM to screen the hybridoma supernatants and for the determination of the Ig class. We also used multi-parametric FCM to characterize the cell-cycle dependent antigen expression. Nuclei were isolated (as previously detailed) using K562 cells harvested during exponential growth and diluted to $20 \times 10^{6}$ nuclei in $2 \mathrm{ml}$ solution A. Fixation was with formaldehyde at final concentration of $1.85 \%$ for $10 \mathrm{~min}$ at room temperature. Nuclei suspensions were washed twice with PBS and divided into different tubes with approximately $3 \times 10^{6}$ nuclei for each tube. Nuclei were centrifuged and incubated for $1 \mathrm{~h}$ on ice with the supernatants in a total volume of $200 \mu \mathrm{l}$ followed by three times washings in PBS*. Routine screening of supernatants was performed by FCM monoparametric analysis by using a secondary anti-Igmouse polyvalent FITC-conjugated antibody added at $1: 100$ dilution in PBS*. Ig class determination of positive clones was performed by monoparametric FCM. Briefly, secondary anti-mouse Ig-specific 
Mabs FITC-conjugated were tested. Fluorescence emission was evaluated in comparison with negative controls obtained using secondary unspecific anti mouse FITC-conj. antibodies.

When positivity of primary Mabs could be demonstrated, cell cycle distribution/dependance of Mabrelated antigens was investigated by means of biparametric FCM. Nuclei were resuspended in $1 \mathrm{ml}$ PBS containing RNase $0.5 \mathrm{mg} / \mathrm{ml}$ and propidium iodide (PI) at $10 \mu \mathrm{g} / \mathrm{ml}$ for list-mode multivariate FCM analysis and sorting as previously described in details [11]. Briefly, we used a FACS 440 dual laser flow sorter system (Becton Dickinson, Mountain View, CA, USA) on line with an IBM-compatible 486 PC or a PDP11 to acquire 4 parameters in list-mode, i.e., red (PI) and green (FITC) fluorescences and forward and perpendicular scattering. Acquisition, storage and data analysis was either with the Phoenix flow system (San Diego, CA, USA) or with the Consort 40 system (Becton-Dickinson) which allowed flexible analysis with use of the "gating" property from only individual or 2-combined parameters.

Results were shown as "isometric contours", which display a three-dimensional distribution of values for any combination of two parameters versus the corresponding number of events given as isocell contour lines.

\subsection{Western blotting and $M W$ determination}

\subsubsection{Extraction and $M W$ determination of whole cells proteins}

About $50 \times 10^{6} \mathrm{~K} 562$ cells at day 3rd of exponential growth were collected and washed one time in cold PBS. Cells were then suspended in distilled water with $0.1 \mu \mathrm{M}$ phenylmethyl-sulfonyl fluoride (PMSF) (Sigma) and $1 \mathrm{mM}$ dithiothreitol (DTT) (Sigma) for $10 \mathrm{~min}$ on ice. After hypotonic lysis, the cell suspension was sonicated repeatedly to complete cellular and nuclear lysis. The sample buffer (sodium dodecil sulfate (SDS) 4\%; glycerol 20\%; Tris(hydroxymethyl)-aminomethane (TRIS) $1 \mathrm{M} \mathrm{12 \%} \mathrm{pH} \mathrm{6.8;}$ bromophenole-blue $0.01 \% ; 2$-mercaptoethanol $0.24 \mathrm{M}$ ) was added at $1: 1$ to the cellular solution and boiled for $5 \mathrm{~min}$. The solution was then used for SDS-PAGE on $8 \%$ acrylamide-containing gels following standard procedures [12]. The AS-2 supernatant was used at a dilution of $1: 2$ in PBS containing heat-inactivated non-immune horse serum (HS) $1 \%$. The secondary antibody, an anti-mouse polyvalent peroxidase-conjugated antibody (Dako, Glostrup, Denmark) was used at the $1: 400$ dilution.

\subsubsection{Extraction and $M W$ determination of cytoplasmic and nuclear proteins}

About $100 \times 10^{6} \mathrm{~K} 562$ cells at day 3rd of exponential growth were collected, divided in two equal samples, and resuspended in $1 \mathrm{ml}$ solution A (see Section 2.1.1), containing $1 \%$ Triton X 100. After being maintained for $30 \mathrm{~min}$ on ice, and repeatedly pipetted to complete the disruption of the cytoplasms, the suspension was centrifuged at 11,200 $\mathrm{g}$ for $10 \mathrm{~min}$. The supernatant, corresponding to the cytoplasmic fraction, and the pellet, corresponding to the nuclear fraction were separately collected. Furthermore, the nuclear suspension was then repeatedly sonicated on ice. The sample buffer was added at $1: 1$ to the cytoplasmic solution and to the nuclear one and boiled for $5 \mathrm{~min}$. The method proceeded as described above for whole cells proteins.

In each case MW determination was assessed by means of molecular weight standards (Sigma) in the range of 29-205 $\mathrm{kDa}$ run in parallel with respect to K562 proteins.

\subsection{Immunofluorescence microscopy}

Human K562 erythroleukemia cells and nuclei were cytocentrifuged to glass slides following standard procedures. Human HeLa cells, instead, were directly grown on microscopic slides. Fixation was done for 10 min in PBS containing 1.85\% formaldehyde, then washed with PBS and permeabilized in solution A 
(see Section 2.1.1) containing $0.5 \%$ Triton $X 100$ for $10 \mathrm{~min}$ at $4{ }^{\circ} \mathrm{C}$. The slides were washed in PBS containing $0.5 \%$ BSA and $0.1 \%$ Triton $\mathrm{X} 100$ and then incubated for $1 \mathrm{~h}$ at room temperature with BSA 5\% in PBS. After the incubation with BSA, the cells were washed again and incubated with AS-2 antibody (supernatant diluted at $1: 2$ in PBS containing HS 1\%) for $1 \mathrm{~h}$ on ice as described previously [13]. Cells were then washed carefully and incubated with a second FITC-conjugated anti-mouse IgM antibody at a dilution of $1: 100$. DNA staining was obtained with the use of $4^{\prime}, 6$-diamidino-2-phenilindole (DAPI) at $0.5 \mu \mathrm{g} / \mathrm{ml}$. Pictures $(1000 \times)$ were taken using a Leitz DMRB immunofluorescence microscope (Wetzlar, Germany).

\section{Results}

FCM screening identified a monoclonal antibody that we named AS-2. Secondary anti mouse IgG and IgM FITC-conjugated antibodies clearly showed that AS-2 was more reactive with anti IgM. Fluorescence emission associated with anti-IgG, in fact, overlapped to the negative control, while the intensity emission associated to IgM was about ten fold higher (Fig. 1).

Western blotting performed on proteins recognized by AS-2 in whole K562 cells showed three clearcut bands of reaction (Fig. 2) of approximate 200, 70 and $60 \mathrm{kDa}$ molecular weights.

Cytoplasmic and nuclear extracts from K562 cells were obtained separately by means of detergent extractions. The $200 \mathrm{kDa}$ molecular weight band was shown to be present only in the cytoplasmic extracts

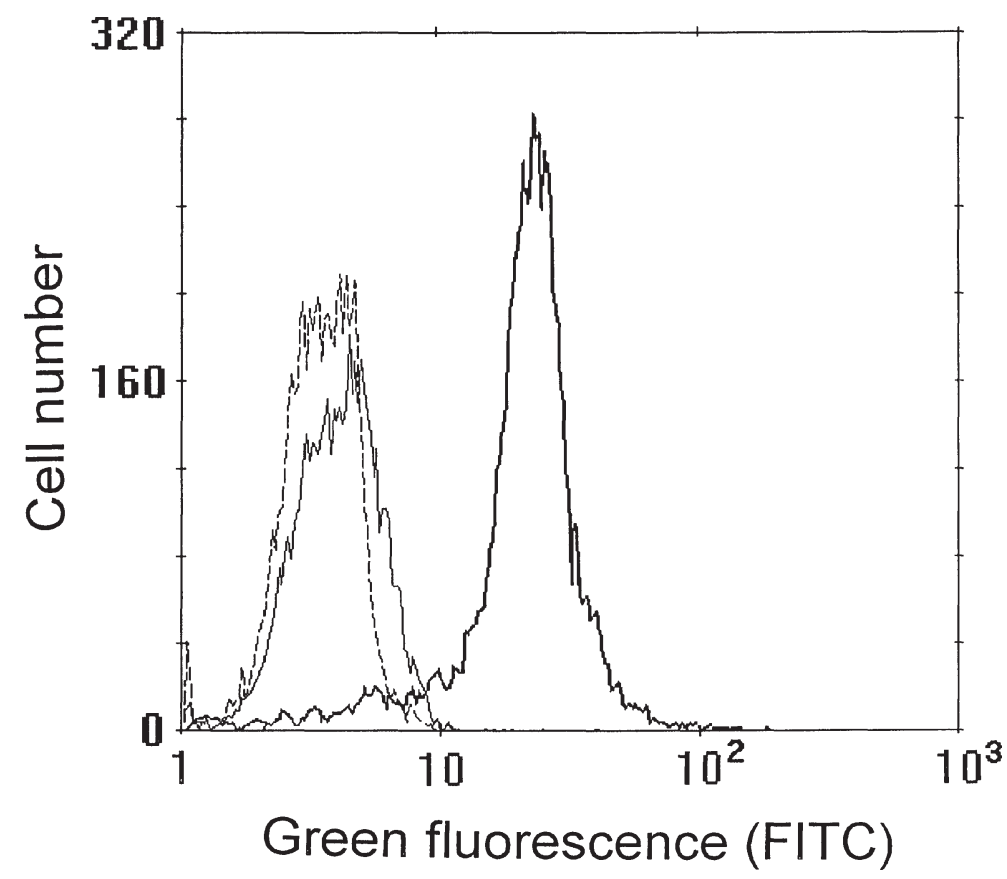

Fig. 1. Flow cytometric Ig class determination of AS-2 antibody. After incubation with primary AS-2, either a secondary specific anti mouse IgG FITC-conjugated antibody (full line) or a specific anti mouse IgM FITC-conjugated antibody (bold line) were used. Negative control was assessed by means of a secondary non-specific FITC-conjugated antibody (broken line). Green fluorescence emission ( $x$ axis) is reported in logarithmic scale, while cell number ( $y$ axis) is in linear scale. Reproducibility of these data was repeatedly tested. 


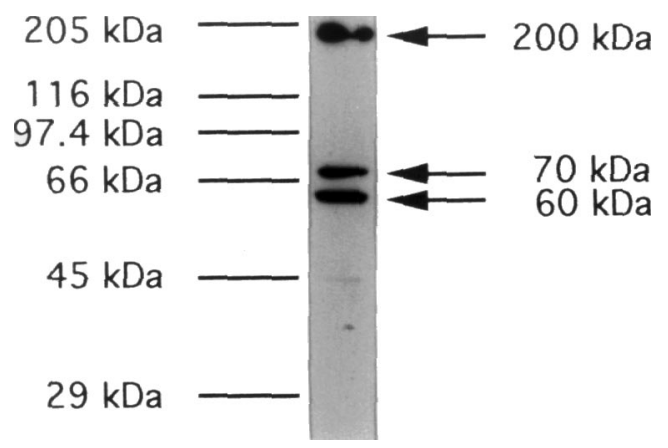

Fig. 2. Western blotting analysis of AS-2 antibody against whole cells extracts of exponentially growing K562. Molecular weight determination was assessed by means of molecular weight markers (range 29-205 kDa). Three reaction bands, indicated by the arrows, have approximate molecular weight of 200, 70 and $60 \mathrm{kDa}$. Reproducibility of these data was repeatedly tested.

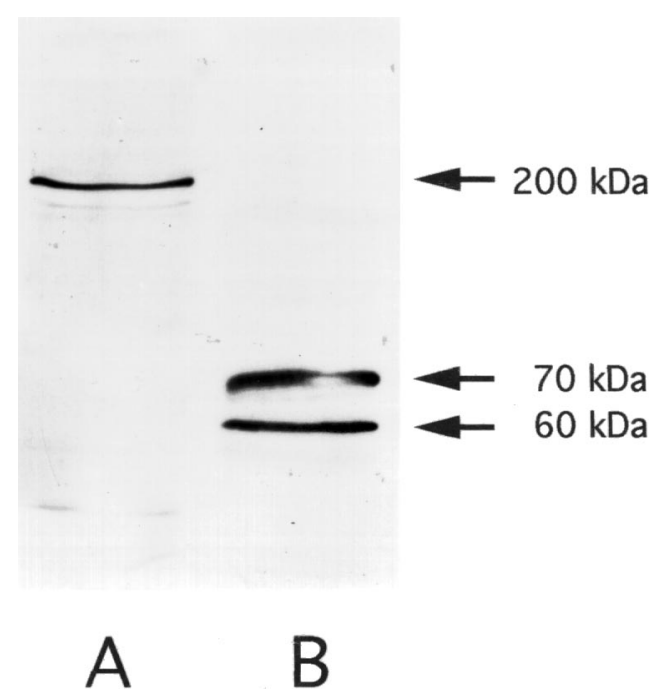

Fig. 3. Western blotting analysis of AS-2 antibody against cytoplasms and nuclei. Cytoplasmic extracts (lane A) and nuclear extracts (lane B) from exponentially growing K562. Molecular weight standards (range 29-205 kDa) were run in parallel. A $200 \mathrm{kDa}$ band in the cytoplasms and two bands of 70 and $60 \mathrm{kDa}$ in the nuclei extracts were found as indicated by arrows. Reproducibility of these data was repeatedly tested.

(Fig. 3(A)), while the two bands of 70 and $60 \mathrm{kDa}$ were both found together in the nuclear extracts (Fig. 3(B)).

Figure 4 shows the relative amount (or, alternatively, the stainability) of the AS-2 recognized proteins in association with DNA content using both nuclei and cell suspensions. One may observe that AS-2 associated fluorescence values (in logarithmic scale with full scale corresponding to 3 decades) using nuclei (Fig. 4(B)) or cells (Fig. 4(F)) were more than 10 times higher than the values of the control nuclei or cells stained with a IgM isotype unspecific antibody (respectively, Fig. 4(A) and Fig. 4(E)).

The slight increase of IgM (FITC) fluorescence from 2C to 4C DNA values in the controls, was unspecifically related to cell/nuclei size increase. One may also observe that AS-2 fluorescence was largely spread for 2C (G1 phase) and 4C (G2 and M phases) DNA values while it was more constant in between $2 \mathrm{C}$ and $4 \mathrm{C}$ ( $\mathrm{S}$ phase). 

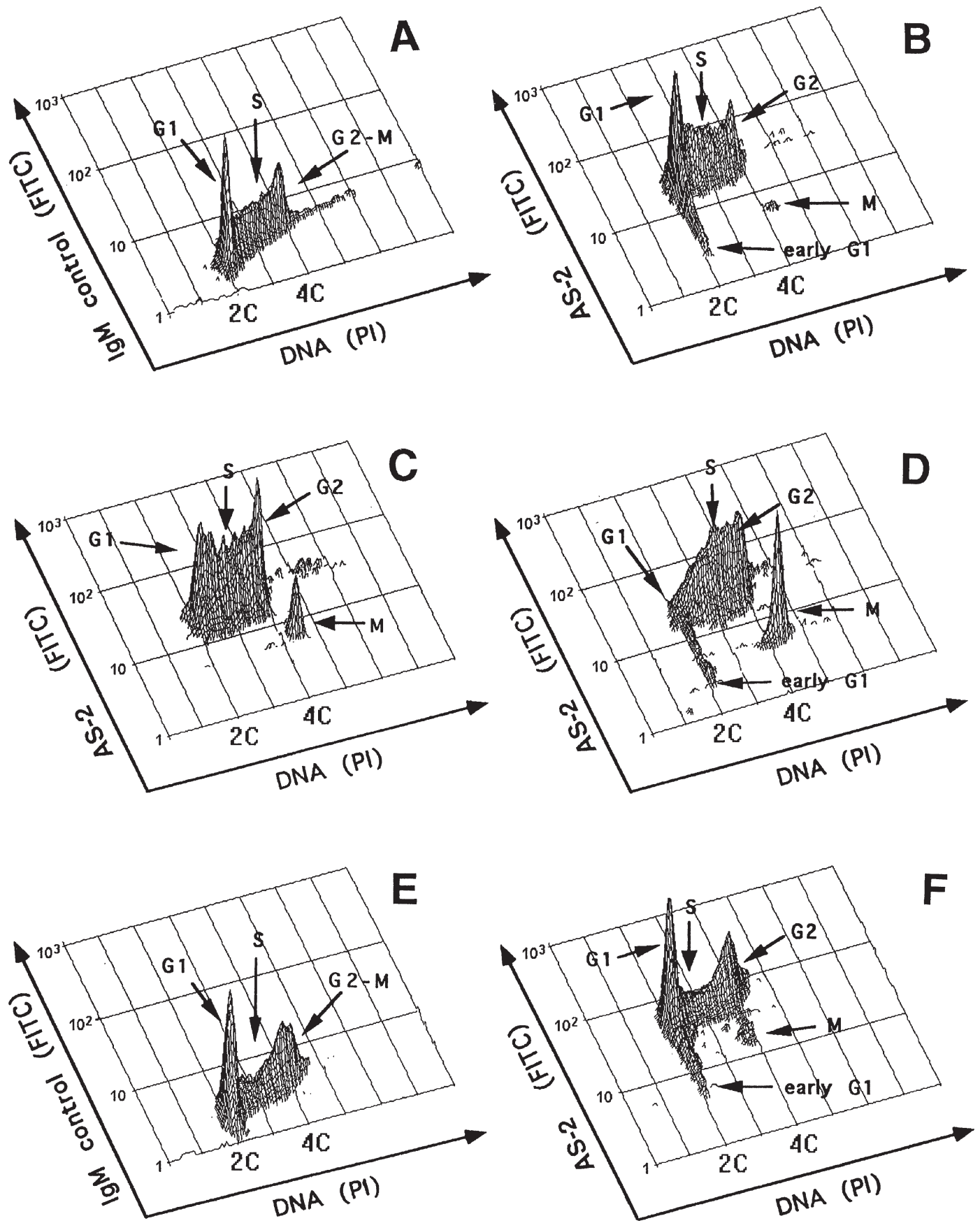

Fig. 4. Multiparameter flow cytometric analysis of the proteins recognized by the AS-2 antibody. FITC-green fluorescence values (logarithmic scale) are shown versus PI-red fluorescence values (linear scale) proportional to DNA content. Data shown are for fixed nuclei suspensions ((A)-(D)) and for whole fixed cell suspensions ((E) and (F)). Negative controls were obtained by means of unspecific IgM and secondary FITC-conjugated Mabs either for nuclei suspension (A) and for cell suspensions (E). The AS-2 protein distribution in nuclei extracted from exponentially growing cells is reported in (B). AS-2 protein distribution in nuclei from cells harvested $2 \mathrm{~h}$ after treatment with colcemid at $0.1 \mu \mathrm{M}$ concentration (C) and $2 \mathrm{~h}$ after colcemid release (D) is shown. AS-2 related fluorescence in exponentially growing cells is shown in (F). Cell cycle phases are indicated by arrows. 
Colcemid block-release experiments were performed to block cells in the $\mathrm{M}$ phase and later to observe the appearance in the $2 \mathrm{C}$ compartment of the early-G1 cell/nuclei. An increase of the "M" subpopulation is clearly visible in Fig. 4(C) after colcemid block. At the same time, a subpopulation of cells with 2C DNA content and low/negative AS-2 fluorescence values completely disappeared. Colcemid release experiments (Fig. 4(D)) showed that this nuclei subpopulation (identified in Fig. 4(D) as early-G1) reappeared. Figure 4(D) also illustrates the dynamics of cells at the colcemid block to release transition in which an accumulation of cells in late-S and G2 phases with absence of late-G1 and early-S cells is clearly visible.

Sorting of cell/nuclei from the interphase and $\mathrm{M}$ compartments was done to help investigating the staining characteristics of AS-2. Nuclei from the early-G1 compartment showed very low to null AS-2 fluorescence. Nuclei at late-G1, S and G2 had a similar positive staining over the entire nuclei. Examples of these staining patterns are shown in Fig. 5.

Figure 5 shows the staining characteristics of AS-2 in interphase and mitotic nuclei and in whole cells by immunofluorescence microscopy. DAPI staining of nuclei cytocentrifuged on slides after AS-2 immunostaining, allowed the identification of nuclei from interphasic cells (Fig. 5(A)) and mitotic events (window in Fig. 5(A)). The same fields in green fluorescence (i.e., AS-2 staining) showed that while two interphasic nuclei were positive, with a staining pattern revealing a regularly interdispersed fluorescence, one nucleus, probably belonging to early-G1 phase, were completely negative to AS-2 immunostaining (Fig. 5(B)). Mitotic events presented a positivity limited to two little, brilliant spots, opposite to each other that likely correspond to the cell centrosomes (window in Fig. 5(B)).

Figures 5(C) and 5(D) show two examples of AS-2 pattern of distribution in whole cells (respectively, cytocentrifuged K562 cells and HeLa cells grown, fixed and immunostained directly on slides). One may observe a diffuse AS-2 positive fluorescence over the entire cytoplasms.

\section{Discussion}

A monoclonal antibody (AS-2) was obtained using K562 extracted nuclei as immunogens. AS-2 (IgM class) recognized three different polypeptides which differed in molecular weights (200, 70 and $60 \mathrm{kDa})$ and were located in the cytoplasm $(200 \mathrm{kDa})$ and in the nucleus (70 and $60 \mathrm{kDa})$. The cytoplasmic proteins appeared easily removable, while the 70 and $60 \mathrm{kDa}$ forms appeared to be strongly bound to nuclear structures.

Multiparameter flow cytometry was used to evaluate the amount of AS-2 positive proteins and DNA content. The highest AS-2 associated fluorescence was for cells or nuclei in the late-G1, S and G2 phases of the cell cycle. The lowest AS-2 fluorescence (at control level) was for early-G1 nuclei and mitoses. Evidence for these last observations was obtained using colcemid treatment that allowed to block cells in $\mathrm{M}$ and then to release the block and to observe cells entering in the early-G1 phase of the cell cycle after telophase.

AS-2 staining pattern has been investigated in both nuclei and cells. AS-2 fluorescence was mainly concentrated in two spots in M, disappeared almost entirely in early-G1 and was again evident over the entire nuclei in late-G1, S and G2 phases of the cell cycle. The proteins recognized by the AS-2 monoclonal antibody appear, therefore, to be degraded before the cells divide or keep a small concentration during the early-G1 postmitotic period. Moreover, these proteins appear to be synthesized up again during the late-G phase of the cell cycle and maintained at high concentration in S and G2 phases.

The present knowledge of the protein recognized by the AS-2 monoclonals is preliminary. The AS-2 recognized proteins in interphase appear to be associated with the nuclear matrix while in mitosis they are 


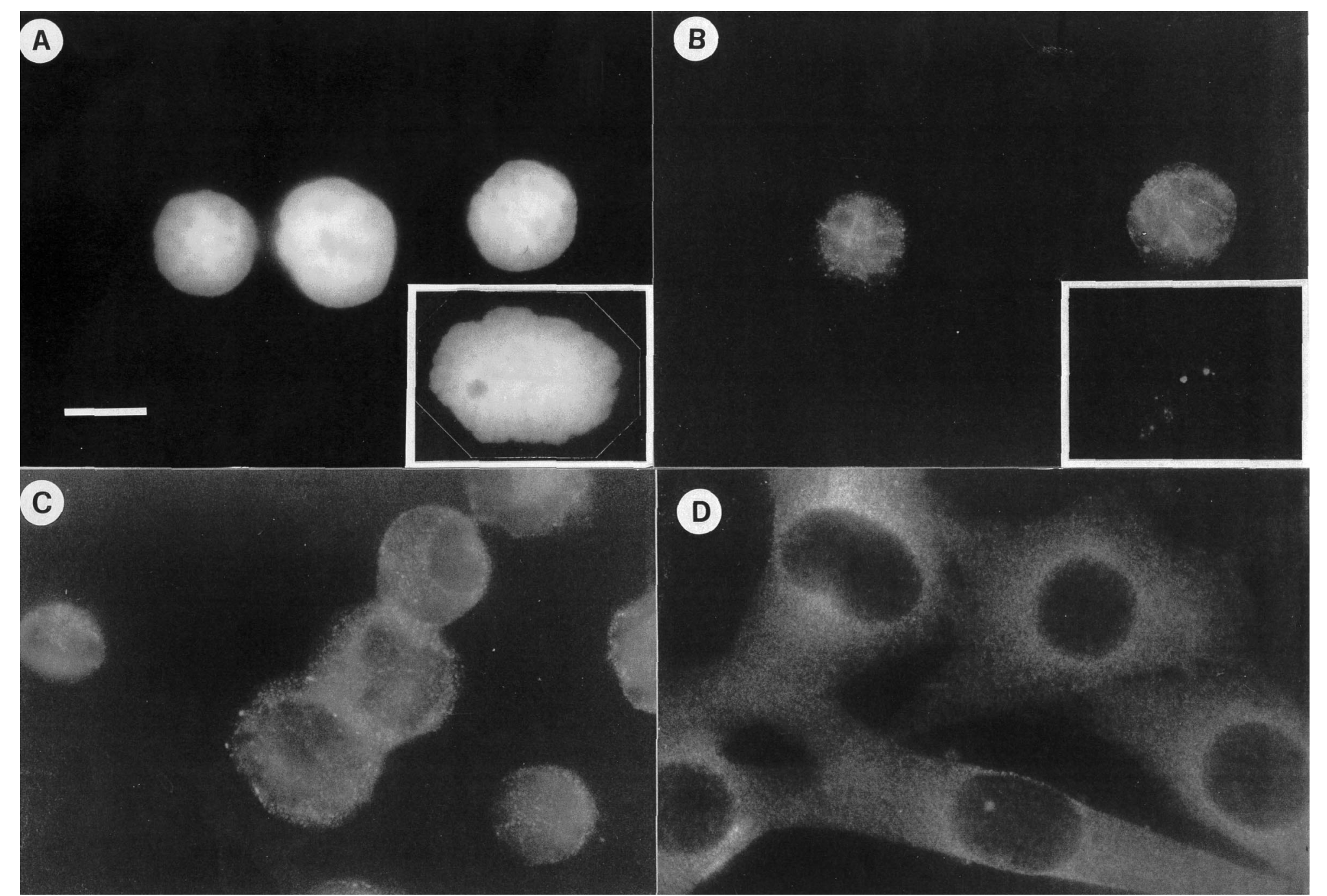

Fig. 5. Nuclear DNA DAPI staining is reported in picture (A). AS-2 immunostaining of the same field is shown in picture (B). While positive nuclei appear stained with interdispersed fluorescence, negativity of the central nucleus is evident. A mitotic cell is shown in the window, stained with DAPI ((A), left side) and with AS-2 (B), right side) for which AS-2 staining is limited to two little dot-like regions opposite to each other. AS-2 cytoplasmic staining patterns for entire cells are shown for K562 (C) and HeLa cells (D), respectively. K562 were cytocentrifuged before fixation while HeLa cells were grown and fixed directly on slides. Bar $=20 \mu \mathrm{m}$ for all the microphotographs. 
visible in two little centrosome-like spots. Colocalization experiments with known proteins of the nuclear matrix and of the centriole associated cell centrosomes are needed to deepen and complete these early findings. In the present study, AS-2 immunofluorescence coupled with FCM indicates a practical mean to separate the G1 phase of the cell cycle in two subphases, i.e., early-G1 and late-G1, with respectively absence and presence of the protein within the nuclei. Moreover, the FCM method we have used allows to clear-cut separate G2-phase cells from the M-phase cells.

AS-2 staining was studied on HeLa cells grown on slides and K562 cells grown in suspension. AS-2 staining was homogeneously dispersed over the entire cytoplasm. The relationship between the nuclear AS-2 recognized nuclear proteins and the AS-2 cytoplasmic proteins, beside the different molecular weights, is so far not known.

In conclusion, we have produced and preliminarily characterized a monoclonal antibody that appears to provide means to investigate the cell cycle in details and could be potentially useful in a number of clinical investigations based on mitoses counting. Further work needs to be done to better understand the role of the AS-2 associated proteins during the cell cycle progression.

\section{Acknowledgements}

This study was financially supported by the National Association for Cancer Research (AIRC), and the Italian Health Ministry. Prof. Guido Damiani (Dept. Biochemistry, University of Genoa) and Dr. Ulrich Pfeffer (Molecular Biology, Advanced Biotechnology Center, Genoa) are also kindly acknowledged for technical help and criticism.

\section{References}

[1] H. Baish and J. Gerdes, Simultaneous staining of exponentially growing versus plateau phase cells with the proliferationassociated antibody Ki-67 and propidium iodide: analysis by flow cytometry, Cell Tissue Kinet. 20 (1987), 387-391.

[2] R.E. Cunningham, Overview of flow cytometry and fluorescence probes for cytometry, Methods Mol. Biol. 34 (1994), 219-224.

[3] Z. Darzynkiewicz, Probing nuclear chromatin by flow cytometry, in: Flow Cytometry and Sorting, M.R. Melamed, T. Lindmo and M.L. Mendelsohn, eds, 2nd edn, Willey-Lyss, New York, 1990, pp. 315-340.

[4] Z. Darzynkiewicz and F. Traganos, Multiparameter flow cytometry in studies of the cell cycle, in: Flow Cytometry and Sorting, M.R. Melamed, T. Lindmo and M.L. Mendelsohn, eds, 2nd edn, Wiley-Lyss, New York, 1990, pp. 469-502.

[5] A. Di Vinci, E. Geido, U. Pfeffer, G. Vidali and W. Giaretti, Quantitative analysis of mitotic and early-G1 cells using monoclonal antibodies against the AF-2 protein, Cytometry 14 (1993), 421-427.

[6] J.R. Dynlacht, J. Henthorn, C. O’Nan, S.T. Dunn and M.D. Story, Flow cytometric analysis of nuclear matrix proteins: method and potential applications, Cytometry 24 (1996), 348-359.

[7] W. Giaretti, A. Di Vinci, E. Geido, B. Marsano, M. Minks and S. Bruno, Measurement of C-myc protein content and cell cycle kinetics of normal and spontaneously transformed murine mastocytes by bivariate flow cytometry, Cell Tissue Kinet. 23 (1990), 473-485.

[8] L. Olson, Human monoclonal antibodies in experimental cancer research, J. Natl. Cancer Inst. 75 (1985), 397-403.

[9] J.P.A. Baak, Manual of quantitative pathology in cancer diagnosis and prognosis, Springer, 1991.

[10] G. Galfre and C. Milstein, Preparation of monoclonal antibodies: strategies and procedures, in: Methods in Enzymology, Vol. 73, J.J. Langone and H. Van Vunakis, eds, Academic Press, New York, 1981, pp. 3-46.

[11] W. Giaretti, M. Nüsse, S. Bruno, A. Di Vinci and E. Geido, A new method to discriminate G1, S, G2, M and G1 postmitotic cells, Exp. Cell Res. 182 (1989), 290-295.

[12] U.K. Laemmli, Cleavage of structural proteins during the assembly of the head of bacteriophage T4, Nature 227 (1970), 680-685.

[13] U. Pfeffer, A. Di Vinci, E. Geido, G. Vidali and W. Giaretti, Cell cycle dependent alterations of chromatin structure in situ as revealed by the accessibility of the nuclear protein AF-2 to monoclonal antibodies, J. Cell Physiol. 149 (1991), $567-574$. 


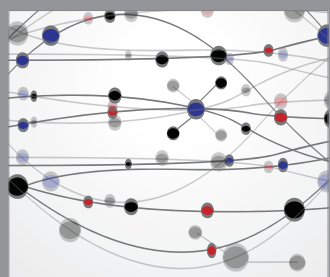

The Scientific World Journal
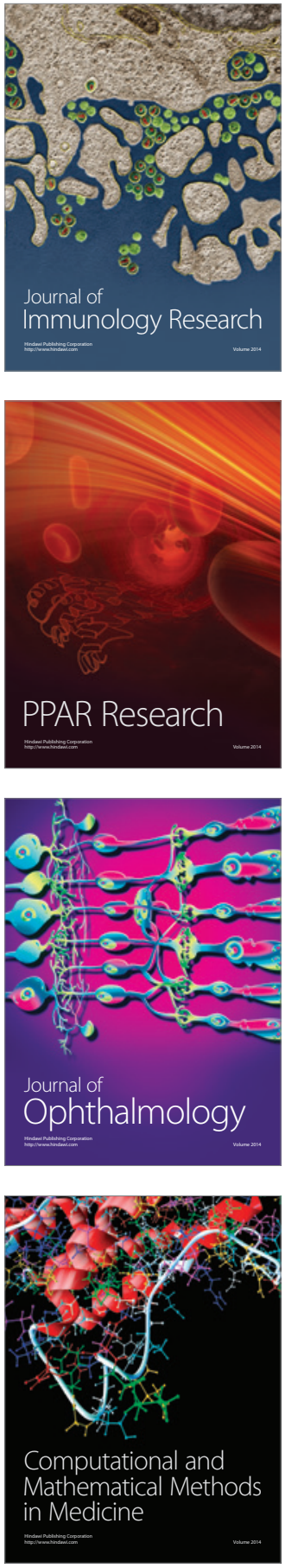

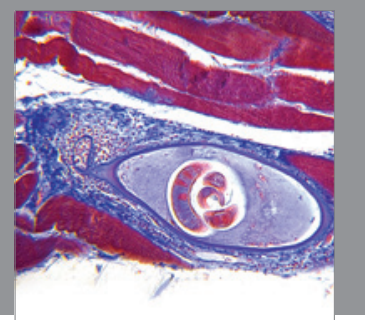

Gastroenterology

Research and Practice
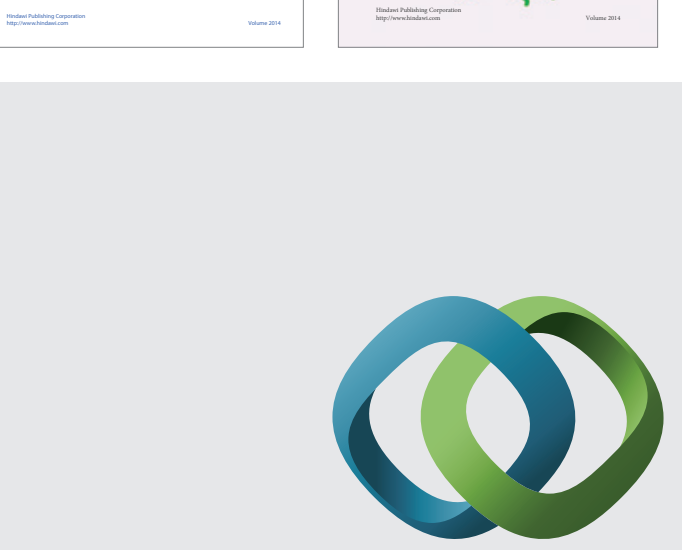

\section{Hindawi}

Submit your manuscripts at

http://www.hindawi.com
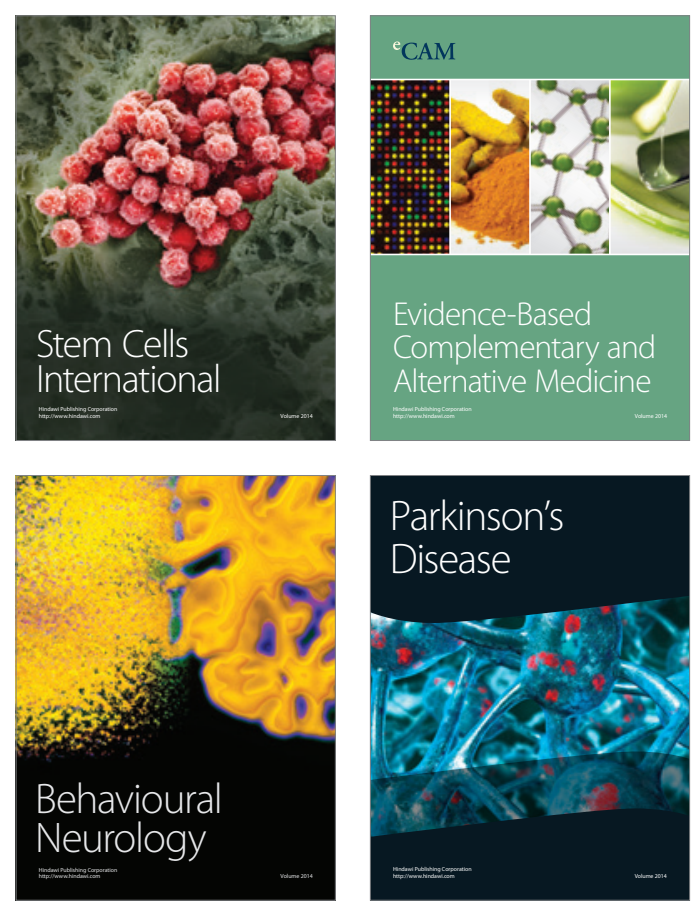

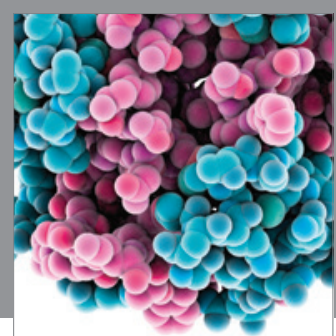

Journal of
Diabetes Research

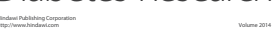

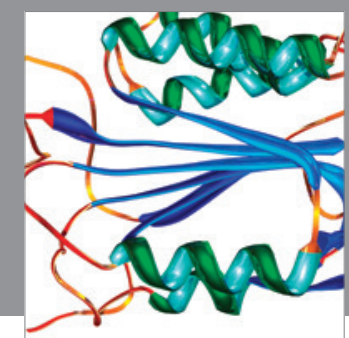

Disease Markers
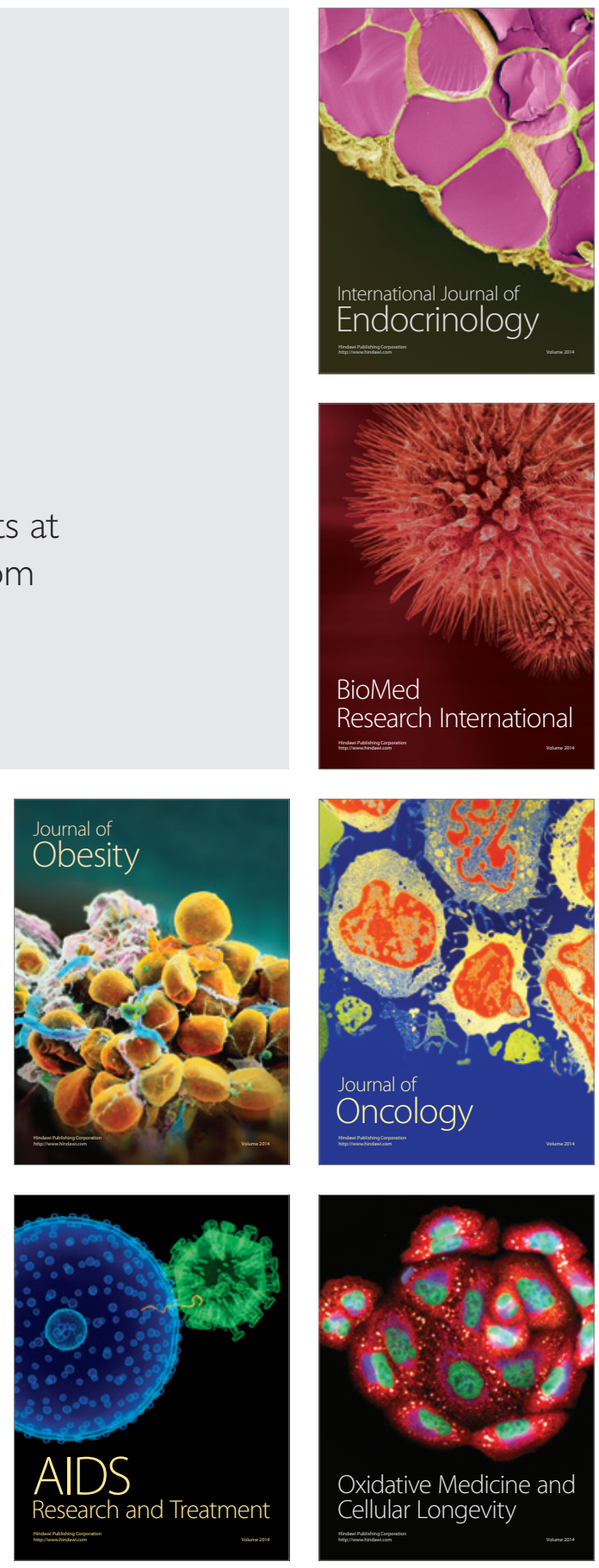